\title{
O USO DOS DISPOSITIVOS ELETRÔNICOS E SUA RELAÇÃO COM O DISPOSITIVO FOUCAUTIANO
}

\author{
Ana Josiane Sutil Miranda* \\ Carina Merkle Lingnau**
}

\begin{abstract}
Resumo: O mundo contemporâneo educacional está conectado a uma forma de ensino mais adequado às necessidades de nossa época, as chamadas metodologias ativas. Essas metodologias muitas vezes são intermediadas por dispositivos eletrônicos, tão comuns no dia-a-dia dos acadêmicos. Nesse trabalho buscamos analisar a relação entre os dispositivos eletrônicos presentes no uso das metodologias ativas e o dispositivo foucaultiano. Como base teórica nos amparamos em Foucault (2008, 2014a, 2014b), Gregolin, Moran, entre outros. Percebemos nos resultados que no portal da Universidade Tecnológica Federal do Paraná (UTFPR) são apresentadas notícias que funcionam como dispositivos foucaultianos sobre o uso de dispositivos eletrônicos como forma de instigar os alunos a serem mediados pelo conhecimento ativo.
\end{abstract}

Palavras-chave: Discurso; Foucault; UTFPR; Iniciação Científica; Metodologias Ativas.

Resumen: El mundo educativo contemporáneo está conectado a una forma de enseñanza más adecuada a las necesidades de nuestro tiempo, las llamadas metodologías activas. Estas metodologías a menudo son intermediadas por dispositivos electrónicos, tan comunes en la vida diaria de los académicos. En este trabajo buscamos analizar la relación entre los dispositivos electrónicos presentes en el uso de metodologías activas y el dispositivo Foucaultiano. Como base teórica nos apoyamos en Foucault (2008, 2014a, 2014b), Gregolin, Moran, entre otros. Notamos en los resultados que en el portal de la Universidad Tecnológica Federal de Paraná (UTFPR) se presentan noticias que funcionan como dispositivos foucaultianos sobre el uso de dispositivos electrónicos como una forma de instigar a los estudiantes a ser mediados por el conocimiento activo.

Palabras claves: Discurso; Foucault; UTFPR; Iniciación Científica; Metodologías activas.

\section{Introdução}

Essa pesquisa faz parte de uma atividade de um semestre de iniciação científica voluntária na Universidade Tecnológica Federal do Paraná, campus Francisco Beltrão

\footnotetext{
" Acadêmica do curso de Engenharia Ambiental na Universidade Tecnológica Federal do Paraná, campus Francisco Beltrão (UTFPR-FB). Professora de dança no município de Francisco Beltrão.

E-mail: anajosiane@hotmail.com

* Professora na Universidade Tecnológica Federal do Paraná, campus Francisco Beltrão (UTFPR-FB). Possui graduação em Letras pela Universidade Federal de Santa Catarina (UFSC). Mestrado em Educação pela Universidade Estadual do Oeste do Paraná (UNIOESTE). Doutorado pela Universidade Estadual de Maringá (UEM). Atualmente orienta alunos de iniciação científica.

E-mail: carinadebeltrao@gmail.com.
}

(UTFPR-FB). A acadêmica envolvida no projeto de pesquisa cursa Engenharia Ambiental na UTFPR-FB. A aluna também já estudou um semestre do curso de Letras na Universidade Federal da Fronteira Sul (UFSS). Atualmente, além de ser graduanda na UTFPR-FB, atua no município de Francisco Beltrão como professora de dança.

Assim, iniciamos a partir de um dos principais questionamentos feitos pelo filósofo francês Michel Foucault: $\mathrm{O}$ que somos, o que somos hoje? Isso ele se preocupou em responder durante sua trajetória de estudo e pesquisas. Mas também e principalmente como a nossa descoberta de quem somos $e$ do que nos compõe poderia nos tornar me-

MIRANDA, Ana Josiane Sutil; LINGNAU, Carina Merkle. O uso dos dispositivos eletrônicos e sua relação com o dispositivo foucautiano. Revista Sul-Americana de Filosofia e Educação. Número 32/33: nov. 2019 - out. 2020, p. 201-205. DOI: https://doi.org/10.26512/resafe.v1i32/33.35122 
lhores e mais autônomos em nossos pensamentos (GREGOLIN, 2016).

Com sua fala e escrita Foucault nos convida a pensar sobre o que reconhecemos como verdade e o que está por trás das escolhas que fazemos. Todas as nossas "verdades" daqui a algum tempo poderão perder a validade e se tornarem ultrapassadas, justamente por vivermos em constante mudança. Mas o que pode fazer essas mudanças acontecerem, respeitando e obedecendo a quais propósitos? Como podem ser produzidas?

Para tentar responder a essas perguntas verificamos que com o passar do tempo passamos também a obter novos pensamentos e atitudes em benefício e/ou malefício de tudo o que está ao nosso redor, porém nem sempre possuímos a consciência disso.

$E$ alguns dos fatos ocorridos que podemos considerar como uma das fontes originárias dessas mudanças são sem dúvida os alcances científicos e tecnológicos. Assim, buscamos nessa pesquisa elencar a metodologia, fundamentação teórica, os resultados e análises, além das considerações e referências.

\section{Metodologia}

Esta pesquisa foi bibliográfica e qualitativa (Bauer e Gaskel, 2002). As análises tiveram como embasamento as leituras $e$ conceitos de Foucault sobre dispositivo (2008, 2014a, 2014b). Para os recortes verificamos as notícias postadas no portal da UTFPR que tinham relação com o assunto dispositivo eletrônico e que apresentam imagens vinculadas ao tema.

\section{Fundamentação teórica}

$\mathrm{Na}$ visão foucaultiana (THOMSON, 2014) diversas são as formas de representação da realidade (pensamento) existente, porém isso não revela necessariamente o real, pois é uma representação culturalmente construída pela realidade, não uma cópia exata (FOUCAULT, 2014). Para Foucault tudo já vem antecedido por um discurso préexistente e que dita a relevância dos múltiplos temas.

Quanto aos dispositivos Gregolin (2016) aponta que Foucault ao falar de dispositivos nos discursos relacionando-os com os canais pelos quais os discursos transitam. Esses canais podem ser instituições, mídias, meios digitais ou documentais que transmitem às massas, os discursos e por serem esses canais respeitados ou tidos como coisas necessárias para se fazer parte do mundo atual, são altamente valorizados e aceitos como muitas vezes, a única verdade.

Nesse nosso mundo contemporâneo de rápidas mudanças por causa do desenvolvimento tecnológico o uso de dispositivos favoráveis à educação, fazendo dos nossos estudantes mais críticos e conscientes de si e do mundo é uma constante. Tem se notado uma necessidade urgente de modernização nos métodos de ensino, especialmente em nosso país, porém há resistência de algumas instituições e grupos para que isso aconteça nas escolas e universidades.

Hoje já não é possível que os professores sejam meros transmissores de conhecimento, já existem na web muitos documentos e sites especializados que disponibilizam acesso ao conhecimento básico e necessário para o processo de formação.

Assim, não há mais espaço para alunos que com todo o acesso disponível sejam 
apenas sujeitos passivos no processo de formação, aceitando tudo como simples ouvintes, eles usam dispositivos eletrônicos e se ligam uns com os outros o tempo todo. Os dispositivos eletrônicos estão nesse trabalho elencados como celulares, tablets, notebooks, GPS, smatphones, etc).

Dessa forma, pensando em tornar nossos estudantes mais ativos, participativos e conscientes dos seus próprios processos de aprendizagem e dos seus verdadeiros papeis no mundo, nasceram as metodologias ativas (MORAN, 2013). Esse processo vem com o objetivo de formar cidadãos mais autônomos, pensantes e responsáveis sobreo que os cercam, capazes de trabalhar de forma excelente em grupo e criar seu próprio caminho.

Essas metodologias trazem novas formas de ensino, terão muitas vezes o professor como mediador cuja responsabilidade será a de traçar os caminhos para que seus alunos se tornem pessoas realizadas em suas aptidões. Este estarão mais próximos destes, conhecerão suas histórias, seus objetivos $e$ os auxiliarão no alcance e no desenvolvimento deles.

\section{Análises \& resultados}

Para as análises tomamos notícias ${ }^{345}$ do portal da UTFPR em que os dispositivos

\footnotetext{
${ }^{3}$ Disponível

em:

http://portal.utfpr.edu.br/noticias/francisco-

beltrao/fechaduras-eletronicas. Acesso em: 17 ago. 2019.

${ }^{4}$ Disponível

http://portal.utfpr.edu.br/noticias/reitoria/tamojunto/estudante-cria-estufa-mais-eficiente-eeconomica. Acesso em: 17 ago. 2019.

${ }^{5}$ Disponível http://portal.utfpr.edu.br/noticias/reitoria/divulgacao-
}

eletrônicos são enfatizados em suas manchetes e imagens, como observamos nas fotos a seguir.

Foto 1 - Aplicativo fará mapeamento de alergias e a relação com a atmosfera

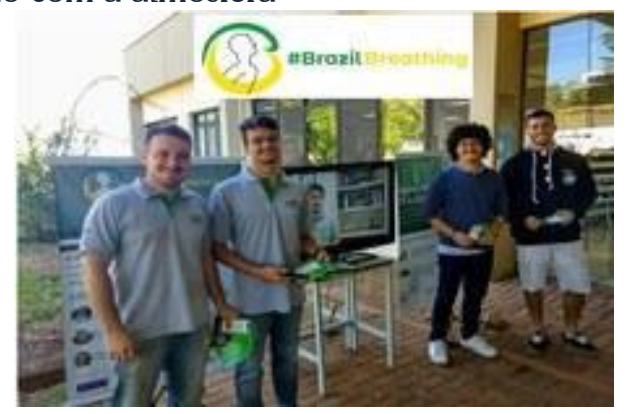

Fonte: portal da UTFPR

Foto 2 - Estudante cria estufa mais eficiente e eco-

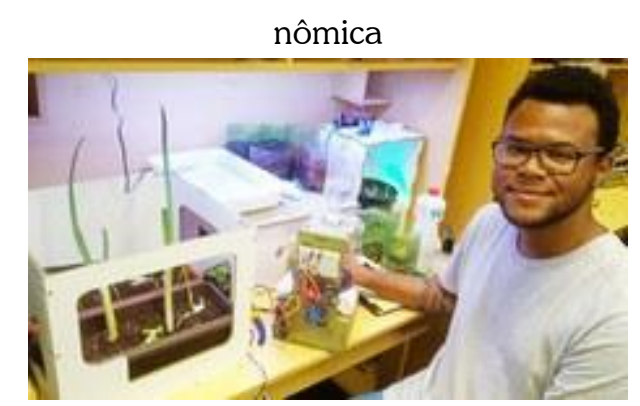

Fonte: portal da UTFPR

Foto 3 - Pesquisa tecnológica aplicada desenvolve dispositivos eletrônicos de segurança para laboratórios do Campus Francisco Beltrão

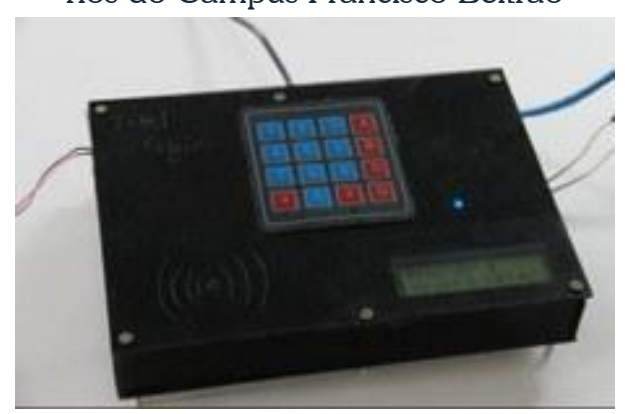

Fonte: portal da UTFPR

A primeira notícia relaciona o aplicativo, sistema a ser instalado em dispositivo móvel, ao dispositivo foucaultiano quando utiliza o canal do discurso da inovação para

cientifica/aplicativo-fara-mapeamento-de-alergias-e-arelacao-com-a-atmosfera. Acesso em: 17 ago. 2019. 
produzir efeito de verdade que caracteriza as notícias do portal da UTFPR. Além disso, inclui o discurso da internacionalização e a pós-graduação para validar o dispositivo.

Os hiperlinks também são usados na notícia para mobilizarem os dispositivos eletrônicos como aliados à verdade produzida na notícia do portal, ou seja, a verdade que aponta a UTFPR como instituição (dispositivo foucaultiano) de inovação associada a seu tempo histórico em que os dispositivos eletrônicos são importantes para que pesquisas e avanços sejam realizados. Pois, para Foucault (2008, p.244) dispositivo é

[...] um conjunto decididamente heterogêneo que engloba discursos, instituições, organizações arquitetônicas, decisões regulamentares, leis, medidas administrativas, enunciados científicos, proposições filosóficas, morais, filantrópicas. Em suma, o dito e o não dito são os elementos do dispositivo. O dispositivo é a rede que se pode estabelecer entre estes elementos.

Nesse caso, os hiperlinks fazem parte das redes que perpassam as instituições envolvidas, os enunciados e a verdade da época, ou seja, o dispositivo eletrônico como sinônimo de tecnologia como algo geral na UTFPR.

$\mathrm{Na}$ segunda manchete e texto verificamos o dispositivo eletrônico relacionado com a inovação (outro dispositivo foucaultiano) que impulsiona a prática do agronegócio ao campo do saber tecnológico e científico, isso também reforça a imagem tecnológica institucional da UTFPR e confirma a correlação entre o dispositivo eletrônico e o foucaultiano.

A última notícia além de apontar o dispositivo eletrônico com bastante evidên- cia, também mostra a questão da vigilância (FOUCAULT, 2008) que tanto está ligada ao dispositivo foucaultiano.

$\mathrm{Na}$ obra Vigiar e punir, Foucault (2014b, p.168) afirma que

o exercício da disciplina supõe um dispositivo que obrigue pelo jogo do olhar: um aparelho onde as técnicas que permitem ver induzam a efeitos de poder, e onde, em troca, os meios de coerção tornem claramente visíveis aqueles sobre quem se aplicam.

A relação dessa passagem com o dispositivo eletrônico de segurança associa o dispositivo foucautiano às verdades construídas no portal da UTFPR. Nessa notícia também é possível validar a presença de cursos de informática na instituição o que igualmente reforça o dispositivo foucaultiano que impulsiona o efeito de verdade da UTFPR como instituição que além de ministrar cursos auxilia a comunidade a solucionar problemas de modo eficiente e técnico.

\section{Considerações finais}

A partir das reflexões em torno dos dispositivos eletrônicos e dos dispositivos foucaultianos temos na experiência de iniciação científica voluntária uma oportunidade de exercitar a leitura e escrita em uma área do conhecimento fundamental para o desempenho de qualquer função.

Essa pesquisa também operou mudanças no olhar das pesquisadoras, na visão de mundo aplicada à própria instituição de ensino $e$ às verdades produzidas sobre a mesma. Ao perder a inocência na atividade de leitura e acesso virtual foi possível identificar a falta de neutralidade quanto aos conteúdos produzidos e veiculados sobre e nas instituições. 
Com base nessa pesquisa somos capazes de identificar possibilidades de interagir com as manchetes e imagens elaboradas em ambientes virtuais $e$ assim analisarmos situações que estejam para além do que foi pesquisado, assumindo assim os papeis de protagonistas no processo de ensinoaprendizagem proposto pelas metodologias ativas.

\section{Referências}

BAUER, Martin. W; GASKEL, George. Pesquisa qualitativa com texto, imagem e som: um manual prático I tradução de Pedrinho A. Guareschi.- Petrópolis, RJ: Vozes, 2002.

COLUNAS TORTAS, O que é discurso? Uma abordagem Foucaultiana. Disponível em: https://colunastortas.com.br/o-que-e-discurso/. Acesso em 16 jul. 2019.

FOUCAULT, Michel. Microfísica do poder. Org e trad. Roberto Machado. 25a .ed. Rio de Janeiro: Edições Graal, 2008.

FOUCAULT, Michel. A arqueologia do saber: Tradução Luiz Felipe Baeta Neves. $8^{\mathrm{a}}$.ed - Rio de Janeiro: Forense Universitária, 2014a.

FOUCAUT, Michel. Vigiar e punir. 20ed. Tradução de Raquel Ramalhete. Petrópolis, Vozes, $2014 b$.

GREGOLIN, Maria do Rosário. Análise do Discurso com Michel Foucault | Ep. 02 Os Dispositivos. Disponível em: https://www.youtube.com/watch?v=IpMURaG9hYc. Acesso em 16 jul. 2019.

MORAN, José, Desafios na implementação do Projeto de Vida na Educação Básica e Superior. Disponível em: http://www2.eca.usp.br/moran/wpcontent/uploads/2019/06/Desafios_Vida1.pdf. Acesso em 16 jul. 2019.

MORAN, José. Metodologias ativas: alguns questionamentos. Disponível em: < http://www2.eca.usp.br/moran/wp-content/uploads/2013/12/metodologias.pdf.> Acesso em 16 jul. 2019.

PORTAL UTFPR. Sobre a UTFPR. Disponível em: http://portal.utfpr.edu.br/institucional/sobrea-utfpr-1. Acesso em 17 Ago. 2019

THOMPSON, Pat. O que é discurso? Uma abordagem Foucaultiana. https://colunastortas.com.br/o-que-e-discurso/. Acesso em: 24 maio de 2019 